\title{
An Economic Comparison between Grid Based and Isolated Rural Electrification in Nepal
}

\author{
Kalyan Malla, Shreejan Pandey, Pat Bodger and Alan Wood \\ Department of Electrical and Computer Engineering \\ University of Canterbury \\ Christchurch, New Zealand \\ E-mail: kalyan.malla@pg.canterbury.ac.nz or spa47@uclive.ac.nz
}

\begin{abstract}
This paper presents a methodology for financial analysis that compares costs and benefits of rural electrification by grid expansion with isolated micro hydro schemes. Financial analysis of three existing isolated micro hydro schemes in different parts of Nepal are compared against the alternative option of grid expansion. Case study results are tabulated and discussed.
\end{abstract}

\section{INTRODUCTION}

In Nepal, common forms of rural electrification (RE) methods adopted in practice are either by expanding the national grid to rural areas or by implementing isolated renewable energy systems such as isolated micro hydro power (MHP). In 2008, Government of Nepal (GoN) had set a target of developing 10,000 MW of hydropower generation by 2020 [1]-[2]. By 2009, Nepal Electricity Authority (NEA) provided about 225,000 rural households with grid supplied and about 55,000 households with isolated small hydro power schemes supplied electricity [3]. This ambitious target has meant the alternative energy sector such as isolated mini or micro hydro power is to provide electricity to about $1,300,000$ rural households by 2020 [4].

Despite the massive scale of RE being undertaken in the country, the conspicuous absence of national electrification framework for the implementation of the RE can adversely affect the aligning of electrification works in a coherent and cost effective manner. The lack of communication and coordination between organizations involved in the micro hydro sector causes delays in RE project execution [4]. In a scenario where both national grid expansion (GE) and isolated electricity generation options are technically feasible, the unavailability of a straightforward financial framework at a national level creates difficulty in deciding the most appropriate option between the two and may sometimes lead to a sub optimal selection.

This paper proposes a simple and comprehensible methodology for financial analysis that can help remove the ambiguity in determining the most financially suitable form of RE. The methodology, accompanied by a block diagram is presented below to determine the most economical option for a given RE scheme. Critical parameters such as applicable project costs and relevant financial indicators that determine financial viability are discussed and used.
The methodology is applied in three RE case studies for different districts of Nepal. Each case study discusses the investment costs, annual operating and maintenance (O\&M) costs, benefit-cost ratio (BCR) and net present value (NPV) for existing MHP. These are compared with the derived financial indicators of corresponding grid expansion option, which is assumed to supply the same load capacity. A cost comparison of the two forms of RE is used to determine the break even grid expansion distance, a point where both forms of electrification have the same investment and O\&M costs while supplying the same load capacity. Grid expansion costs are primarily distance dependent and the existing MHP investment costs mostly depend on the generation capacity.

Factors such as quality of electricity, cost of electricity generation for grid expansion schemes, and consumer reliability costs are not compared here and are considered beyond the scope of this paper. However, there is limited end use for electricity other than for lighting in the rural communities of Nepal and therefore the quality of electricity is unlikely to make a noticeable difference to end users in the near future. Income generating end user enterprises with high load demand for few hours a day are difficult to develop in remote locations because markets are small and isolated [4]. Hence, consumer reliability costs are treated as irrelevant.

Two of the three MHPs selected for case study were completed in 2006 [5]-[6]. Hence, all cost and monetary values are in US Dollar (US\$) 2006 rates.

\section{PROPOSED METHODOLOGY}

Fig. 1 and the following steps summarise the proposed methodology.

Step 1: Recommendations on the technical viability and environmental impact assessment of the two RE options are solicited and studied with reference to the existing standard detailed technical feasibility study (DTFS) and the initial environment examination (IEE) standards [7]-[8].

Step 2: If both DTFS and IEE approve implementation of both grid expansion and isolated electrification, then financial assessments are performed according to the salient features and socio-economic status of each option. This process involves determining the total investment cost and estimating 
the annual operation and maintenance (O\&M) costs along with other key financial indicators.

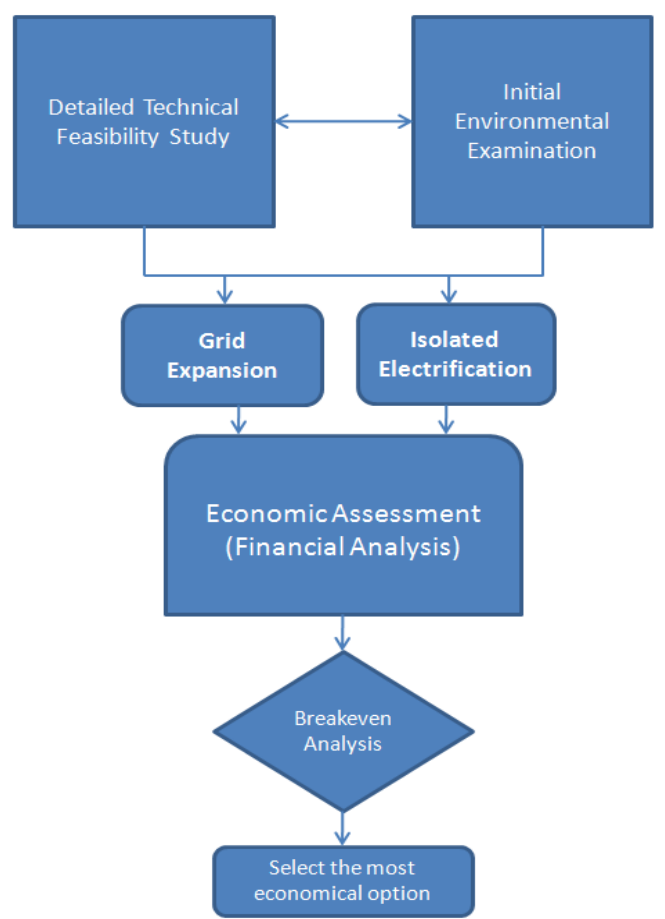

Figure 1. Proposed methodology for selection of a RE option.

Financial indicators such as annual income generated by electricity sales, annual O\&M cost and loan repayment commitment are used to calculate annual cash flow for each option:

$$
C F=A I-A E
$$

where $\mathrm{CF}$ : cash flow, $\mathrm{AI}$ : annual income and $\mathrm{AE}$ : annual expense.

The total lifetime (normally fifteen years) and an applicable discount rate (between $4 \%$ and $10 \%$ ), depending on the financial climate is used to calculate the RE's net present value (NPV) [9]:

$$
N P V=\sum_{t=0}^{n} \frac{C F_{t}}{(1+r)^{t}}
$$

where $\mathrm{t}$ : year of operation, $\mathrm{n}$ : lifetime of project in years, and $\mathrm{r}$ : discount rate.

Annual income, annual loan repayment and annual O\&M costs are used to calculate benefit-cost ratio (BCR) [9]:

$$
B C R=\frac{\sum_{t=0}^{n} \frac{A I_{t}}{(1+r)^{t}}}{\sum_{t=0}^{n} \frac{A O \& M+L R+E_{t}}{(1+r)^{t}}}
$$

where AO\&M: annual O\&M costs, LR: annual loan repayment costs and E: initially invested equity. NPV and BCR are used to check the financial viability of each RE option.
Step 3: A breakeven analysis is driven by the financial assessment results and calculates the breakeven grid expansion distance. Beyond this distance, electrification by isolated local rural generation scheme becomes economically more worthwhile.

The total investment cost of isolated rural generation electrification scheme includes an assessment of transportation costs, the cost of transporting resources to a remote site. Transportation of equipment by local manpower to site within two days of walking distance from the nearest road head are found to be $0.7 \%$ and $1.05 \%$ of the total capital investment cost[5]-[6],[10]. For sites that are extremely isolated, transportation costs can add up to $25 \%$ of total investment costs [11]. Therefore, it is safe to assume a "fixed" total investment cost for isolated generation projects that are located within two days of walking distance from the nearest road head. For more remote sites, daily labour rate and the number of labourers required per day and/or aerial transport costs need to be accounted for to determine a distance based variable total investment cost.

GE cost is primarily distance based and variable according to the site location and the nearest existing grid location,

$$
G E_{c}=C I_{\text {perkm }} \times D
$$

where $\mathrm{GE}_{\mathrm{c}}$ : capital investment of grid expansion, CIperkm: initial capital investment per kilometre and D: distance of expansion required.

The lifetime cost gives the total cost of a RE scheme for its lifetime in present value terms. It adds the initial capital investment cost with the net present value of recurring annual $\mathrm{O} \& \mathrm{M}$ costs. It is:

$$
L C_{G E}=\left(C I_{\text {perkm }}+\left(\sum_{t=1}^{n} \frac{A O \& M_{t}}{(1+r)^{t}}\right)_{\text {perkm }}\right) \times D
$$

where $\mathrm{LC}_{\mathrm{GE}}$ : lifetime cost of a grid expansion scheme.

MHP lifetime cost is primarily based on the generation capacity of the scheme. It is:

$$
L C_{M H P}=C I+\sum_{t=1}^{n} \frac{A O \& M_{t}}{(1+r)^{t}}
$$

where $\mathrm{LC}_{\mathrm{MHP}}$ : lifetime cost of the MHP scheme.

The lifetime cost of isolated generation and the total lifetime grid expansion cost per kilometre are compared on a lifetime cost versus distance plot to obtain the breakeven grid expansion distance.

Step 4: Financial indicators and the breakeven grid expansion distance obtained in step 2 and step 3 are compared to provide a basis for the selection of an economically justifiable RE option. 


\section{CASE STUDIES}

Financial benefits and costs of three existing micro hydro schemes in different parts of Nepal were analysed and compared with the alternative option of grid expansion. The financial parameters for micro hydro schemes are based on real figures associated with each scheme. The financial parameters derived for GE schemes are based on typical figures associated with NEA's GE costs per kilometre, interest rates, discount rates and tariff rates[5]-[6], [10], [12]. A break-even grid expansion distance point was derived for each case. Key financial parameters of the three case studies are presented in Tables I, II and III.

\section{A. Daram One MHP Scheme}

Daram One MHP scheme $(100 \mathrm{~kW})$ is located in Rishmi village, Baglung, western Nepal. It is located approximately 20 $\mathrm{km}$ away from the nearest road access and approximately $8 \mathrm{~km}$ away from the nearest distribution lines connected to the national grid. The existing MHP was commissioned in 2006 and supplies electricity to 990 households, one agro processing mill, one bakery and one furniture workshop [5].

TABLE I.

FINANCIAL PARAMETERS OF DARAM ONE

\begin{tabular}{lcc}
\hline \hline Financial Parameter & MHP & GE \\
\hline total investment cost & $\$ 237,950$ & $\$ 88,707$ \\
annual O\&M cost & $\$ 9,820$ & $\$ 2,661$ \\
loan & $\$ 51,845$ & $\$ 88,707$ \\
interest rate & $16 \%$ & $10 \%$ \\
discount rate & $6 \%$ & $5 \%$ \\
tariff rate (residential) & $\$ 0.03 / \mathrm{W} /$ month & $\$ 0.055 / \mathrm{kWh}$ \\
tariff rate (commercial) & $\$ 0.08 / \mathrm{kWh}$ & $\$ 0.75 / \mathrm{kWh}$ \\
net present value & $\$ 85,529$ & $\$ 170,404$ \\
scheme lifetime & 15 years & 15 years \\
\hline \hline
\end{tabular}

\section{B. Fakfok Two MHP Scheme}

Fakfok Two MHP (20 kW) scheme is located in Saptin village of Ilam, eastern Nepal. It is located approximately 2.5 $\mathrm{km}$ away from the nearest road access and approximately 5 $\mathrm{km}$ away from the nearest distribution lines connected to the national grid. The existing MHP was commissioned in 2006 and supplies electricity to 230 households and two agro processing business enterprises [6].

\section{Kisedi MHP Scheme}

Kisedi MHP scheme $(21 \mathrm{~kW})$ is located in Pachok village, Lamjung, central Nepal. During project implementation, it was located approximately $11.5 \mathrm{~km}$ away from the nearest road access and approximately $8 \mathrm{~km}$ away from the nearest distribution lines connected to the national grid. The existing MHP was commissioned in January, 2010 and supplies electricity to 194 households, one agro processing mill, two furniture workshops, one poultry farm and one small mill [10].
TABLE II.

FINANCIAL PARAMETERS OF FAKFOK TWO

\begin{tabular}{lcc}
\hline \hline Financial Parameter & MHP & GE \\
\hline total investment cost & $\$ 47,087$ & $\$ 55,442$ \\
annual O\&M cost & $\$ 2,811$ & $\$ 1,580$ \\
loan & $\$ 0$ & $\$ 55,442$ \\
interest rate & $12 \%$ & $10 \%$ \\
discount rate & $4 \%$ & $5 \%$ \\
tariff rate (residential) & $\$ 0.020 / \mathrm{W} / \mathrm{month}$ & $\$ 0.055 / \mathrm{kWh}$ \\
tariff rate (commercial) & $\$ 0.083 / \mathrm{kWh}$ & $\$ 0.075 / \mathrm{kWh}$ \\
net present value & $\$ 6,558$ & $\$ 2,446$ \\
scheme lifetime & 15 years & 15 years \\
\hline \hline
\end{tabular}

TABLE III.

FINANCIAL PARAMETERS OF KISEDI

\begin{tabular}{lcc}
\hline \hline Financial Parameter & MHP & GE \\
\hline total investment cost & $\$ 45,954$ & $\$ 82,464$ \\
annual O\&M cost & $\$ 2,780$ & $\$ 2,623$ \\
loan & $\$ 6,894$ & $\$ 82,464$ \\
interest rate & $16 \%$ & $10 \%$ \\
discount rate & $4 \%$ & $5 \%$ \\
tariff rate (residential) & $\$ 0.014 / \mathrm{W} / \mathrm{month}$ & $\$ 0.055 / \mathrm{kWh}$ \\
tariff rate (commercial) & $\$ 0.07 / \mathrm{kWh}$ & $\$ 0.075 / \mathrm{kWh}$ \\
net present value & $\$ 3,397$ & $\$ 2,080$ \\
scheme lifetime & 15 years & 15 years \\
\hline \hline
\end{tabular}

\section{RESULTS}

Capital investment cost includes costs associated with all civil works, electro-mechanical works, tools and spare parts, installation, commissioning tests and transportation of equipment. Capital cost does not include the recurring annual O\&M costs. Equation (4) is used to define the capital investment costs of grid expansion. Capital investment cost for Daram Khola One MHP is $\$ 237,950$ [5]. This is 2.7 times higher than $\$ 88,708$, the calculated capital investment cost for the corresponding grid expansion option. Capital cost comparison economically favours grid expansion for Daram One. Isolated MHP scheme is favoured over grid expansion options for Fakfok-2 and Kisedi as shown in Figure 1.

Equations (5) and (6) are used to determine lifetime project costs. The lifetime cost of Daram One MHP is $\$ 333,324$. This is 2.9 times higher than $\$ 116,331$, the calculated lifetime cost of grid expansion. Lifetime cost comparison favours grid expansion for Daram Khola one. MHP lifetime cost is \$6,504 higher than the lifetime cost of grid expansion for Fakfok two. Other factors such as the comparison of benefit-cost ratio and end user requirements are important to consider in this case. Kisedi MHP lifetime cost is $\$ 32,828$ less than the lifetime cost 
of grid expansion. Hence, the comparison favours Kisedi MHP over grid expansion.

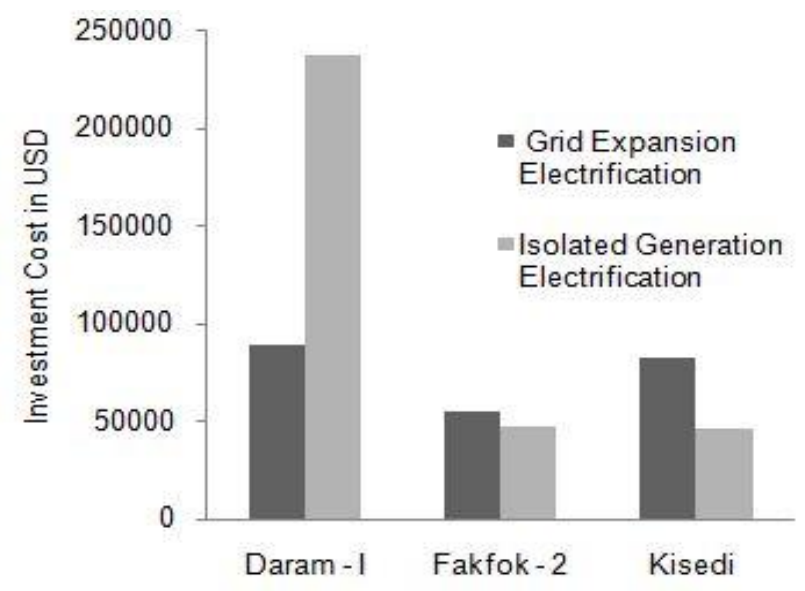

Figure 1. Electrification capital investment cost comparison between existing MHP schemes and corresponding grid expansion options.

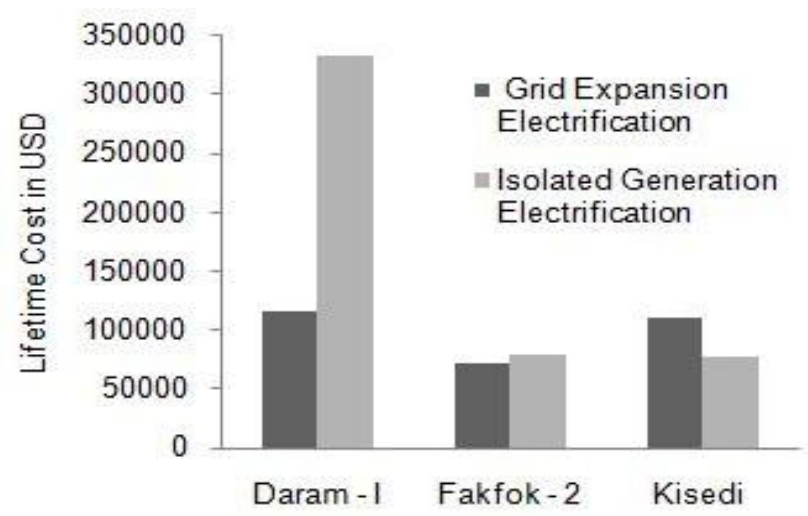

Figure 2. Electrification lifetime cost comparison between existing MHP schemes and corresponding grid expansion options.

Benefit (B) is the lifetime income generated in present value terms and Cost $(\mathrm{C})$ is the lifetime costs of all expenditure in present value terms. In order for an investment to be financially viable, the BCR must be greater than 1 . BCR for Daram One grid expansion is 2.39; this is 1.7 times higher than the existing MHP with BCR of 1.38. BCR comparison favours grid expansion over MHP for Daram One. Fakfok Two and Kisedi MHP's higher BCRs ratios suggest that MHPs have a greater return of investment than grid expansion.

\section{A. Break Even Grid Expansion Distance Points}

Equations (5) and (6) are used to derive grid expansion and MHP lifetime costs. Fixed MHP lifetime cost and distance dependent grid expansion costs are compared on a plot to obtain a break even grid expansion distance. Table IV shows the break even grid expansion distance points for all three cases. It shows the existing Daram Khola One MHP was not an attractive investment; grid expansion would have rather been a wiser option for this scheme based on grid expansion distance, higher BCR and NPV.
Fakfok Two MHP is arguably located on the break even distance point and not a bad investment. Existing Kisedi MHP is favoured over the option of grid expansion.

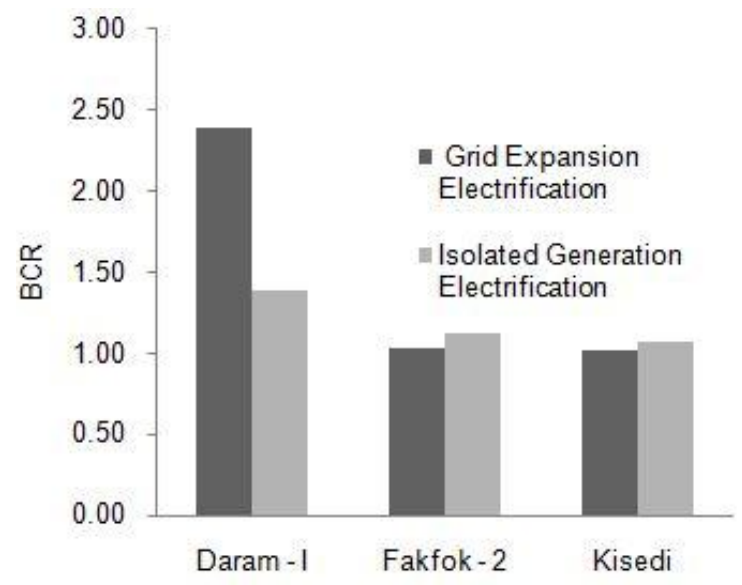

Figure 3. BCR comparison between existing MHPs and corresponding grid expansion options.

TABLE IV.

GRID EXPANSION BREAK EVEN DISTANCES

\begin{tabular}{ccc}
\hline \hline MHP Scheme & $\begin{array}{c}\text { Grid Location } \\
\text { from MHP } \\
\text { scheme }(\mathbf{k m})\end{array}$ & $\begin{array}{c}\text { GE Break Even } \\
\text { Distance } \\
(\mathbf{k m})\end{array}$ \\
\hline Daram One & 8 & 23 \\
Fakfok Two & 5 & 5.6 \\
Kisedi & 8 & 5.8 \\
\hline \hline
\end{tabular}

Capital investment cost, lifetime cost, BCR and grid expansion break even distance analysis suggest the existing Daram One MHP was not the most attractive financial investment and Kisedi MHP a good financial investment. Fakfok Two MHP is arguably located on the grid expansion break even distance point and not a bad financial investment given the BCR and capital investment cost favour MHP over grid expansion.

\section{CONCLUSION}

Rural electrification by grid expansion and isolated micro hydro power systems are the two most commonly implemented RE methods in Nepal. This paper presents a simple methodology that can be used at the national level to invest in the most economically efficient rural electrification option. The proposed methodology compares key financial indicators (lifetime cost, cash flow, net present value, and benefit cost ratio) between isolated micro hydro power schemes and corresponding grid expansion schemes.

Financial benefits and costs of three existing micro hydro schemes in different parts of Nepal were compared with the alternative options of grid expansion. A break-even grid expansion distance point was derived for each case. Results showed that one existing micro hydro scheme, Daram One was economically less attractive than grid expansion. Grid expansion option would have been economically more efficient 
because it delivers a higher Benefit to Cost Ratio. Existing Kisedi micro hydro scheme was an economically attractive investment. Existing Fakfok Two micro hydro scheme is located just past the grid expansion distance break-even point but has a higher Benefit to Cost Ratio; therefore, Fakfok Two is considered a good investment option.

This paper shows that simple economic comparison can help determine the most economical rural electrification scheme. Such economic comparison at an early stage of rural electrification project can contribute in making the best use of scarce technical and financial resources and facilitate implementation of RE works. In a broader national context, it can have a positive impact to the socio-economic development of Nepal.

\section{REFERENCES}

[1] Nepal Hydropower Association, "The Nepal Hydropower Database 2009," Kathmandu, Annual Report 2009.

[2] Hydro Nepal, Vision 2020: Hydro power- A Vision for Growth, January 2009.

[3] Nepal Electricity Authority, "A Year in Review, Fiscal Year 2008/09," Nepal Electricity Authority, Kathmandu, Annual Report 2009.

[4] Energy Sector Assistance Programme, "Annual Progress Report 2065/66," Alternative Energy Promotion Centre, Government of Nepal, Kathmandu, Nepal, Annual Report 2009.

[5] Oshin Power Service Pvt. Limited, "Detailed Feasibility Study Report of Daram-1 MHP," Oshin Power Service Pvt. Limited, Butwal, Nepal, Feasibility Report 2006.

[6] Alternative Energy Promotion Centre, Energy Sector Assistance Programme, "Detailed Feasibility Study Report of Fakfok-II micro hydro project," Kathmandu, Nepal, Feasibility Report 2006.
[7] Mini Grid Support Programme, Energy Sector Assistance Programme and Alternative Energy Promotion Centre, "Guidelines For Detailed Feasibility Study of Micro Hydro Projects," Kathmandu, Standard Guideline 2003.

[8] Government of Nepal, "National Environmental Assessment Guidelines," Nepal Gazette, vol. 43, no. 5, 1993.

[9] W. G. Sullivan, J. A. Bontadelli and E. P. DeGarmo, "Engineering Economy," 9th ed., D. Johnstone, Ed. New York, USA: Macmillan Publishing Company, 1993.

[10] D.Rajbhandari, Alternative Energy Promotion Centre, Kisedi MHP Data, Nepal, July, 2010, Private Communication.

[11] S. Khennas and A. Barnett, "Best practices for sustainable development of micro hydro power in developing countries," The Intermediate Technology Development Group, Warwickshire, UK, Synthesis Report March. 2000.

[12] Nepal Electricity Authority, Small Hydro and Rural Electrification Department, "Costing norms for rural electrification networks - fiscal year 2008/09," Kathmandu, Annual report 2009. 